\title{
Influência da temperatura na solubilidade de $\beta$-caroteno em solventes orgânicos à pressão ambiente
}

\author{
Effect of temperature on the solubility of $\beta$-carotene in organic solvents under ambient pressure
}

\author{
Marcus Vinícius TRÊS ${ }^{1}$, Elton FRANCHESCHI ${ }^{1}$, Gustavo Rodrigues BORGES ${ }^{1}$, Cláudio DARIVA², \\ Fernanda de Castilhos CORAZZA루, José Vladimir OLIVEIRA ${ }^{1}$, Marcos Lúcio CORAZZA ${ }^{1 *}$
}

\begin{abstract}
Resumo
O presente trabalho reporta dados experimentais de solubilidade em pressão ambiente de $\beta$-caroteno em solventes orgânicos puros (etanol, acetona, acetato de etila e diclorometano) e em misturas de tais solventes no intervalo de temperatura de 10 a $60^{\circ} \mathrm{C}$. Para este fim, adotouse o método gravimétrico para a determinação da solubilidade, utilizando células encamisadas de equilíbrio. Os resultados mostraram que valores mais elevados de solubilidade são obtidos quando foram empregados solventes com parâmetros de solubilidade mais próximos daquele do soluto. Verificou-se que o aumento da temperatura, tanto para solventes puros, como para as misturas de solventes, acarretou num aumento da solubilidade do $\beta$-caroteno para todas as condições experimentais. Observou-se ainda, que nas condições experimentais investigadas, não houve sinergismo significativo para as misturas de solventes quando comparadas aos valores de solubilidade obtidos para os solventes puros. O modelo UNIFAC se mostrou útil na previsão qualitativa dos resultados de solubilidade.

Palavras-chave: $\beta$-caroteno; solubilidade; solventes orgânicos; UNIFAC.
\end{abstract}

\begin{abstract}
This work reports experimental data of the solubility of $\beta$-carotene in pure acetone, ethyl acetate, ethanol and dichloromethane and in mixtures of these organic solvents in the temperature range of 10 to $60^{\circ} \mathrm{C}$ under ambient pressure. The gravimetric method was employed to determine the solubility, using glass equilibrium cells. The results showed that the best solvents were those having solubility parameter values close to that of the solute. It was found that raising the temperature caused the solute solubility values for both pure and solvent mixtures to increase under all the experimental conditions. Moreover, no synergetic effects were observed on the solubility of $\beta$-carotene in solvent mixtures compared to pure solvents in the temperature range investigated. The UNIFAC model proved to be useful in predicting the solubility data.
\end{abstract}

Keywords: $\beta$-carotene; solubility; organic solvents; UNIFAC.

\section{Introdução}

Nas últimas duas décadas houve nítida intensificação de pesquisas envolvendo carotenóides, tendo este segmento recebido considerável atenção por parte de profissionais de diferentes áreas do conhecimento, tais como químicos orgânicos, químicos de alimentos, biólogos, médicos e ambientalistas ${ }^{12}$. Além da crescente busca por produtos que contenham em sua formulação compostos naturais ${ }^{24,26}$, o interesse pelos carotenóides se justifica tendo em vista que tais compostos têm sido propostos como agentes de ação preventiva ao câncer, inibidores de úlceras, rejuvenescedores, inibidores de ataques do coração ${ }^{3,5,8,14,16}$, bem como têm sido utilizados na imunização e inseminação artificial do gado ${ }^{4,9}$.

Os carotenóides apresentam a estrutura básica de tetraterpenos formados por oito unidades isoprenóides de cinco carbonos, ligados de tal forma que a molécula é linear e simétrica com a ordem invertida no centro. Este esqueleto básico pode ser modificado por diferentes rotas, tais como reações de hidrogenação, desidrogenação, ciclização, migração de dupla ligação,

Recebido para publicação em 23/11/2006

Aceito para publicação em 24/8/2007 (002084)

Departamento de Engenharia de Alimentos,

Universidade Regional Integrada - URI, Campus de Erechim

Av. Sete de Setembro, 1621, CEP 99700-000, Erechim - RS, Brasil,

E-mail:mlcorazza@uri.com.br

Instituto de Tecnologia e Pesquisa - ITP, Aracaju - SE, Brasil

3 Mestrado em Engenharia de Processos - PEP, Universidade Tiradentes - UNIT,

Campus Farolândia, Av. Murilo Dantas, 300, CEP 49031-490,

Aracaju - SE, Brasil

*A quem a correspondência deve ser enviada encurtamento ou extensão da cadeia, rearranjo, isomerização, introdução de substituintes e oxidação. O sistema de duplas ligações conjugadas confere a estes pigmentos alta reatividade química, podendo ser facilmente isomerizados e oxidados ${ }^{15,17}$. Os carotenóides hidrocarbonetos são chamados de carotenos e os derivados oxigenados, de xantofilas. Os carotenóides mais comuns são o $\beta$-caroteno, o licopeno, a luteína e a zeaxantina ${ }^{6}$. O $\beta$-caroteno, cuja fórmula estrutural plana é apresentada na Figura 1, é conhecido como pró-vitamina A.

A vitamina A desempenha importante papel na manutenção da visão, participando da púrpura visual, que tem por função a visão na luz fraca. Além disso, participa da proteção da pele e de mucosas e atua ainda no metabolismo das gorduras. Quando o $\beta$-caroteno entra no metabolismo humano, uma parte é transformada em vitamina A e o restante fica retido para futuras necessidades. Segundo a Organização Mundial de Saúde, mais de 250 milhões de pré-escolares, particularmente em países em desenvolvimento, apresentam deficiência de vitamina A. No Brasil, onde a hipovitaminose A é considerada uma das principais deficiências na área de Saúde Pública, a larga distribuição destes pigmentos em frutos e vegetais aliada ao alto custo dos alimentos de origem animal que contêm vitamina A pré-formada, contribuem para que os carotenóides se constituam em uma importante fonte deste nutriente na dieta humana ${ }^{1,19}$.

Atualmente, os carotenóides utilizados comercialmente são obtidos por rota sintética ou por extração a partir de plantas e algas. A procura por compostos com conotação na- 


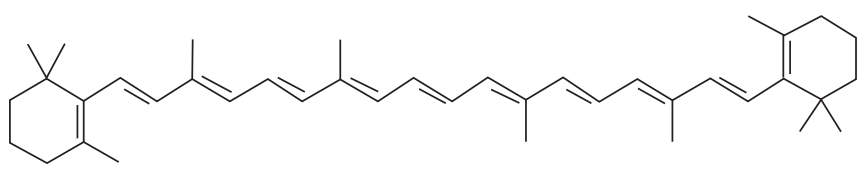

Figura 1. Fórmula estrutural plana do $\beta$-caroteno ${ }^{21}$.

tural tem resultado num incremento de pesquisas referentes à produção de carotenóides por via fermentativa em processos biotecnológicos ${ }^{7,13,23}$. No entanto, cabe ressaltar que, a exemplo dos processos extrativos, no processo fermentativo também se faz necessária a extração com solventes orgânicos e posterior recuperação do soluto.

Ademais, tendo em vista a baixa estabilidade dos carotenóides à luz, as etapas de obtenção, manuseio e embalagem dos mesmos requerem cuidado especial visando reduzir sua oxidação. Neste cenário, técnicas de microencapsulamento destes em matrizes poliméricas empregando solventes pressurizados têm sido propostas na literatura ${ }^{22}$. A produção de micro e nano partículas com características controladas vem despertando grande interesse na área alimentícia e nutracêutica. $O$ fator chave que determina a funcionalidade e as propriedades de aplicação de um determinado material sólido micro ou nano particulado é o tamanho de partícula, a distribuição de tamanho de partícula, a morfologia e a configuração da rede cristalina além da possibilidade de co-precipitação ${ }^{11}$.

No que diz respeito às técnicas para produção de micro e nano partículas, spray drying e moagem ultrafina figuram certamente entre as mais comuns. A maior desvantagem destas técnicas, no entanto, é que geralmente obtém-se uma larga distribuição de tamanho das partículas e somente uma pequena parte destas é produzida na faixa micrométrica ou nanométrica. Além disso, o emprego de temperaturas, da ordem de $100{ }^{\circ} \mathrm{C}$, para o processamento por spray drying torna esta técnica pouco atrativa para compostos termosensíveis. Na moagem, um grande stress mecânico é freqüentemente causado, podendo modificar a estrutura interna das partículas produzidas. Partículas ultrafinas podem também ser preparadas utilizando o processo de precipitação empregando anti-solventes líquidos. As limitações primárias desta técnica incluem dificuldades em conter e controlar o crescimento das partículas e uma eliminação efetiva dos solventes líquidos das partículas ${ }^{10}$. Conseqüentemente, altos custos de operação, etapas pós-processamento e baixos rendimentos estão associados a estas técnicas.

Uma vez que partículas com tamanho nanométrico ou de alguns micras são muito difíceis de serem obtidas usando métodos tradicionais, várias técnicas baseadas em fluidos pressurizados têm sido propostas no sentido de explorar as características de manipulação do poder solvente e da alta difusividade, que são peculiares dos fluidos nas proximidades do ponto crítico ${ }^{22}$. O uso de fluidos sub ou supercríticos como anti-solventes na produção de partículas tem sido demonstrado por diversos pesquisadores como útil na modificação das propriedades de materiais como o tamanho de partícula, distribuição de tamanho, estrutura cristalina e morfologia. Outra característica destas técnicas reside na eficiente separação do solvente e anti-solvente das partículas após a precipitação.
É possível, então, evitar resíduos de solventes no produto e oferecer um reaproveitamento potencialmente vantajoso do solvente e do anti-solvente ${ }^{20}$.

O conhecimento da solubilidade de carotenóides em solventes orgânicos é de fundamental importância para o desenvolvimento de processos de recristalização empregando anti-solventes pressurizados. Em que pese a importância do $\beta$-caroteno no contexto atual, a busca na literatura aberta revelou a existência de um único trabalho referente à determinação da solubilidade deste carotenóide em solventes orgânicos ${ }^{4}$. Tais autores reportaram valores de solubilidade do $\beta$-caroteno, a temperatura ambiente em 18 solventes orgânicos, obtidos através do método da absorbância das amostras em espectrofotômetro, empregando a Lei de Beer para quantificação. Não se verificou também, até o presente momento, a existência de trabalhos referentes à solubilidade de $\beta$-caroteno em misturas de solventes orgânicos.

O presente trabalho visa fornecer subsídios fundamentais ao desenvolvimento de processos de produção de micro/nano partículas, ao encapsulamento do referido carotenóide em fluidos pressurizados e aos processos de extração de carotenóides produzidos por via fermentativa. Neste sentido, esta investigação tem por objetivo avaliar o efeito da temperatura sobre a solubilidade de $\beta$-caroteno em solventes e mistura de solventes orgânicos, especificamente em acetato de etila, acetona, diclorometano e etanol, e em misturas de acetato de etila e etanol, acetato de etila e diclorometano e diclorometano e etanol.

\section{Material e métodos}

\subsection{Materiais}

Trans- $\beta$-caroteno tipo I sintético com pureza aproximada de $95 \%$ foi adquirido da Sigma-Aldrich. Quanto aos solventes orgânicos: acetato de etila e acetona, ambos com pureza mínima de $99,5 \%$, são de procedência Quimex, enquanto que diclorometano (pureza mínima de 99,5\%) e etanol (pureza mínima de 99,9\%) são de procedência Merck. Cumpre aqui ressaltar que, à exceção do diclorometano, os demais solventes orgânicos utilizados neste trabalho são ecologicamente corretos e aceitos na indústria alimentícia. Justifica-se, no entanto, o uso do diclorometano como referencial tendo em vista seu potencial de solubilização, e que seu possível emprego em misturas possa contribuir para redução de seu grau de toxicidade. Todos os reagentes empregados neste trabalho foram utilizados sem nenhum tratamento prévio.

\subsection{Aparato e procedimento experimental}

A faixa de temperatura investigada no presente trabalho situa-se entre 10 e $60{ }^{\circ} \mathrm{C}$, região esta comumente encontrada em processos de formulação de micropartículas empregando tecnologia supercrítica e que cobre a faixa utilizada em processos fermentativos para produção de carotenóides. Para alguns solventes, diclorometano e acetona, o limite superior foi reduzido em função da alta volatilidade dos mesmos. Nas medidas experimentais envolvendo misturas, foram avaliadas 
proporções em base volumétrica de 1:3, 1:1 e 3:1 dos solventes binários.

O método gravimétrico foi adotado para a obtenção dos dados de solubilidade do $\beta$-caroteno. As medidas foram conduzidas em células de equilíbrio encamisadas, construídas em vidro com capacidade para $60 \mathrm{~mL}$, dotadas de tampa de teflon. O aparato experimental utilizado é esquematicamente apresentado na Figura 2. No total foram avaliadas 213 condições experimentais. Todas as análises foram realizadas em triplicatas autênticas, de modo a permitir uma estimativa da incerteza experimental associada.

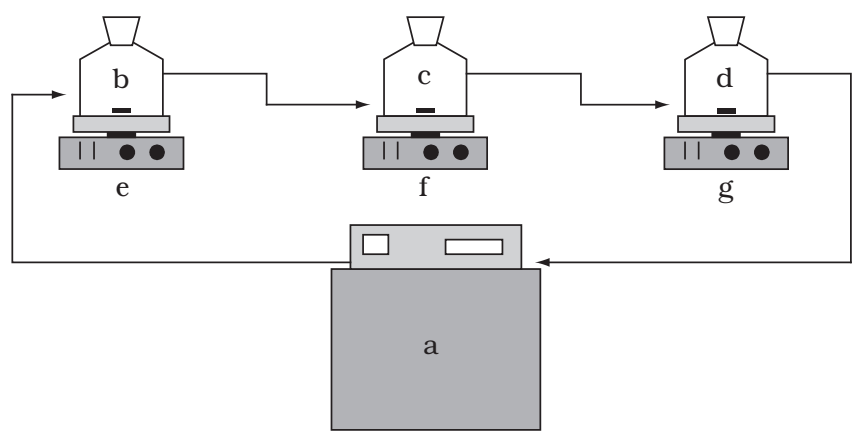

Figura 2. Diagrama esquemático do aparato experimental. a) banho termostatizado (Nova Ética, modelo 521/3D); b, c e d) células de equilíbrio de vidro encamisadas; e f e g) sistema de agitação (Fisatom, modelo 752A).

O procedimento experimental consistia no acionamento do banho termostático, ajustando-se a temperatura desejada para o experimento através de leituras efetuadas por termopares (PT-100), previamente calibrados, devidamente posicionados em cavidades ("poços") existentes nas células de equilíbrio. Nesta etapa eram colocadas as barras magnéticas e adicionados cerca de $30 \mathrm{~mL}$ de solvente ou mistura de solventes no interior das células. Adicionava-se a seguir em torno de 0,3 g de $\beta$-caroteno no interior de cada célula e acionava-se o sistema de agitação. Decorrido determinado período de tempo, caso a solução se mantivesse totalmente translúcida, adicionava-se nova quantidade de $\beta$-caroteno e mantinha-se a solução sob agitação. O procedimento era repetido até que a solução apresentasse sólidos em excesso. O sistema era então mantido sob agitação por no mínimo 12 horas e então deixado em repouso (sem agitação) à temperatura constante, antes da retirada das amostras. Testes preliminares realizados com retiradas de amostra em tempos crescentes conduziram ao estabelecimento de 24 horas de repouso como período adequado à condução dos experimentos realizados.

A amostragem era realizada pipetando-se $5 \mathrm{~mL}$ da solução sobrenadante com auxílio de uma pipeta volumétrica previamente calibrada. As amostras eram transferidas para béqueres de $50 \mathrm{~mL}$, previamente pesados, e levados à estufa a $60^{\circ} \mathrm{C}$ por 24 horas para evaporação completa do solvente. Após este tempo, os béqueres eram acondicionados em dessecador, e em seguida pesados (balança Gibertini, modelo E154, precisão de 0,0001 g), determinando-se a massa de soluto. Os resultados de solubilidade são reportados em $\mathrm{mg}$ de $\beta$-caroteno por $\mathrm{mL}$ de solução.

\section{Resultados e discussão}

\subsection{Solubilidade de $\beta$-caroteno em solventes puros}

A Tabela 1 apresenta os valores de solubilidade de $\beta$-caroteno em solventes orgânicos puros, ao passo que a dependência com a temperatura pode ser mais adequadamente observada através da Figura 3. Os resultados apresentados nesta figura mostram que para todos os solventes utilizados neste trabalho o aumento da temperatura conduziu a um aumento, ainda que tímido para o caso do etanol, da solubilidade do $\beta$-caroteno. De acordo com a teoria das soluções regulares de Scatchard-Hildebrand ${ }^{18}$, que prevê unicamente desvios positivos da idealidade, solventes com valores de parâmetros de solubilidade ${ }^{2}$ mais próximos do exibido pelo soluto ${ }^{12}$ implicam em coeficientes de atividade mais próximos da unidade e, conseqüentemente, maiores valores de solubilidade, fato este observado experimentalmente para os sistemas solutosolvente investigados neste trabalho. Também, considerando que em tal teoria a entropia em excesso é nula, a dependência prevista pelo modelo da solubilidade com a temperatura é a mesma daquela observada experimentalmente, corroborando, portanto, do ponto de vista termodinâmico, o comportamento experimental observado.

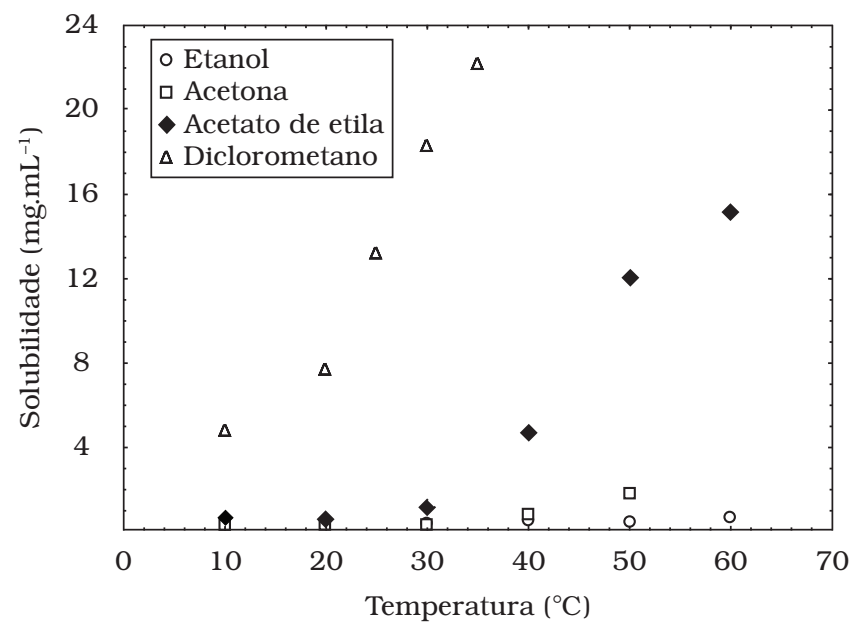

Figura 3. Solubilidade do $\beta$-caroteno em solventes orgânicos em função da temperatura.

A título ilustrativo apresenta-se na Figura 4 uma comparação entre os resultados experimentais e aqueles calculados empregando-se o modelo UNIFAC ${ }^{27,25}$ para o sistema $\beta$-caroteno + acetato de etila, de onde é possível observar a boa concordância entre experimento e teoria, considerando a natureza totalmente preditiva do modelo empregado.

A Tabela 2 apresenta a comparação entre os dados experimentais de solubilidade de $\beta$-caroteno a $20{ }^{\circ} \mathrm{C}$ em alguns solventes orgânicos obtidos neste trabalho e os reportados na 
Tabela 1. Solubilidade de $\beta$-caroteno nos solventes orgânicos estudados e desvio padrão das medidas experimentais.

\begin{tabular}{cccc}
\hline Solvente & $\begin{array}{c}\text { Temperatura } \\
\left({ }^{\circ} \mathrm{C}\right)\end{array}$ & $\begin{array}{c}\text { Solubilidade } \\
\left(\mathrm{mg}^{\left.-\mathrm{mL}^{-1}\right)}\right.\end{array}$ & $\begin{array}{c}\text { Desvio padrão } \\
\left(\mathrm{mg}^{\mathrm{m}} \mathrm{mL}^{-1}\right)\end{array}$ \\
\hline Acetato de etila & 10 & 0,680 & $\pm 0,212$ \\
& 20 & 0,627 & $\pm 0,081$ \\
& 30 & 1,153 & $\pm 0,242$ \\
& 40 & 4,733 & $\pm 0,117$ \\
& 50 & 12,060 & $\pm 0,370$ \\
Acetona & 60 & 15,180 & $\pm 0,311$ \\
\hline Diclorometano & 10 & 0,193 & $\pm 0,249$ \\
& 20 & 0,307 & $\pm 0,202$ \\
& 30 & 0,340 & $\pm 0,251$ \\
& 40 & 0,787 & $\pm 0,444$ \\
& 50 & 1,820 & $\pm 0,191$ \\
\hline Etanol & 20 & 4,767 & $\pm 0,141$ \\
& 25 & 7,693 & $\pm 0,133$ \\
& 30 & 13,193 & $\pm 0,204$ \\
& 35 & 18,250 & $\pm 1,061$ \\
& 10 & 22,160 & $\pm 0,193$ \\
\hline 20 & 0,207 & $\pm 0,162$ \\
& 30 & 0,360 & $\pm 0,106$ \\
& 40 & 0,400 & $\pm 0,072$ \\
& 50 & 0,540 & $\pm 0,191$ \\
& 60 & 0,487 & $\pm 0,266$ \\
& & 0,700 & $\pm 0,191$ \\
\hline
\end{tabular}

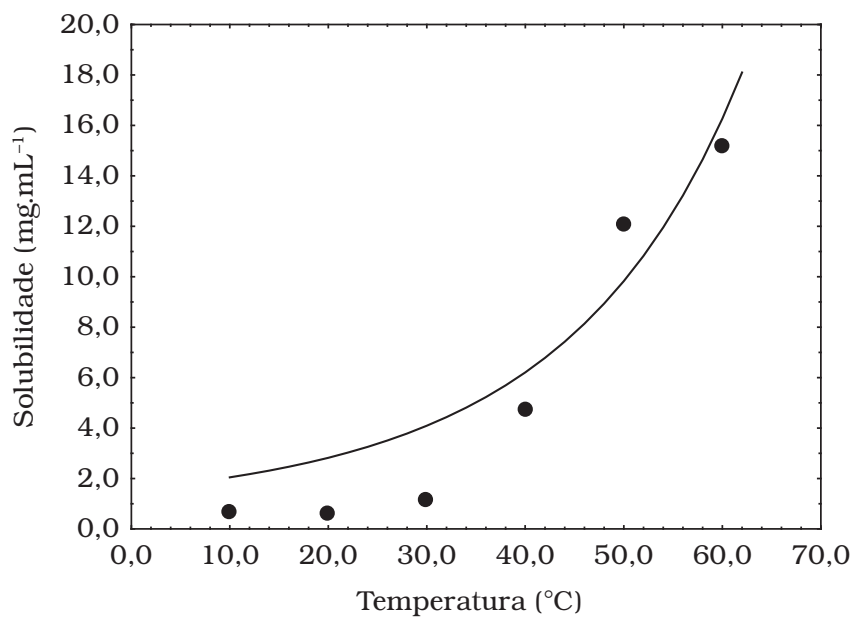

Figura 4. Comparação entre valores experimentais e calculados pelo modelo UNIFAC da solubilidade de $\beta$-caroteno em acetato de etila em função da temperatura.

Tabela 2. Comparação entre os resultados experimentais de solubilidade de $\beta$-caroteno a $20^{\circ} \mathrm{C}$ obtidos neste trabalho com os reportados na literatura.

\begin{tabular}{lcc}
\hline \multirow{2}{*}{ Solvente } & \multicolumn{2}{c}{ Solubilidade $\left(\mathrm{mg} \cdot \mathrm{mL}^{-1}\right)$} \\
\cline { 2 - 3 } & Literatura $^{10}$ & Este trabalho \\
\hline Acetato de etila & 0,500 & $0,627 \pm 0,081$ \\
Acetona & 0,200 & $0,307 \pm 0,202$ \\
Diclorometano & 6,000 & $7,693 \pm 0,133$ \\
Etanol & 0,030 & $0,360 \pm 0,106$ \\
\hline
\end{tabular}

literatura. A comparação dos valores obtidos neste trabalho com os reportados na literatura ${ }^{4}$ indica que a técnica gravimétrica apresentou-se como satisfatória para a determinação da solubilidade de $\beta$-caroteno em solventes orgânicos, cabendo observar a discrepância marcante verificada entre as fontes para o sistema contendo etanol. Para este sistema específico, novos experimentos foram executados e verificou-se excelente reprodutibilidade dos valores reportados. Para os outros solventes, possivelmente a diferença possa ser explicada em termos de erros experimentais aleatórios, diferenças quanto aos lotes/procedências dos solventes empregados e também pela omissão do valor de temperatura (ambiente) utilizada nos experimentos da literatura.

\subsection{Solubilidade de $\beta$-caroteno em misturas de solventes}

\section{Mistura etanol (EtOH) + acetato de etila}

Os valores de solubilidade de $\beta$-caroteno na mistura etanol: acetato de etila estão reportados na Tabela 3 , enquanto que a Figura 5 apresenta a variação da solubilidade em função da composição da mistura de solventes e da temperatura. É interessante observar nesta figura o comportamento não linear exibido pela solubilidade em função da concentração, comportamento este também previsto pelo método UNIFAC.

Tabela 3. Solubilidade de $\beta$-caroteno nas misturas dos solventes etanol (EtOH) (1) + acetato de etila (2) nas temperaturas de 10, 20, 30,50 e $60{ }^{\circ} \mathrm{C}$.

\begin{tabular}{cccc}
\hline $\begin{array}{c}\text { Temperatura } \\
\left({ }^{\circ} \mathrm{C}\right)\end{array}$ & $\begin{array}{c}\text { Proporção de etanol: } \\
\text { acetato de etila }\left(\mathrm{v} \cdot \mathrm{v}^{-1}\right)\end{array}$ & $\begin{array}{c}\text { Solubilidade } \\
\left(\mathrm{mg}_{\mathrm{mL}}{ }^{-1}\right)\end{array}$ & $\begin{array}{c}\text { Desvio padrão } \\
\left(\mathrm{mg} \cdot \mathrm{mL}^{-1}\right)\end{array}$ \\
\hline 10 & $3: 1$ & 0,430 & $\pm 0,156$ \\
& $1: 1$ & 0,587 & $\pm 0,304$ \\
& $1: 3$ & 0,793 & $\pm 0,214$ \\
\hline 20 & $3: 1$ & 0,220 & $\pm 0,072$ \\
& $1: 1$ & 0,313 & $\pm 0,273$ \\
& $1: 3$ & 0,787 & $\pm 0,273$ \\
\hline 30 & $3: 1$ & 0,200 & $\pm 0,140$ \\
& $1: 1$ & 0,467 & $\pm 0,239$ \\
& $1: 3$ & 0,580 & $\pm 0,216$ \\
\hline 50 & $3: 1$ & 0,320 & $\pm 0,080$ \\
& $1: 1$ & 0,887 & $\pm 0,031$ \\
& $1: 3$ & 1,787 & $\pm 0,122$ \\
\hline 60 & $3: 1$ & 0,933 & $\pm 0,281$ \\
& $1: 1$ & 1,513 & $\pm 0,189$ \\
& $1: 3$ & 2,880 & $\pm 0,191$ \\
\hline
\end{tabular}

A partir dos resultados apresentados na Tabela 3 e na Figura 5, pode-se verificar um aumento da solubilidade do $\beta$-caroteno em relação ao aumento da temperatura e na proporção de acetato de etila em quase todas as condições experimentais.

\section{Mistura etanol $(\mathrm{EtOH})+$ diclorometano (DCM)}

Os valores de solubilidade de $\beta$-caroteno na mistura de solventes orgânicos etanol e diclorometano encontram-se reportados na Tabela 4 e apresentados na Figura 6. Através 


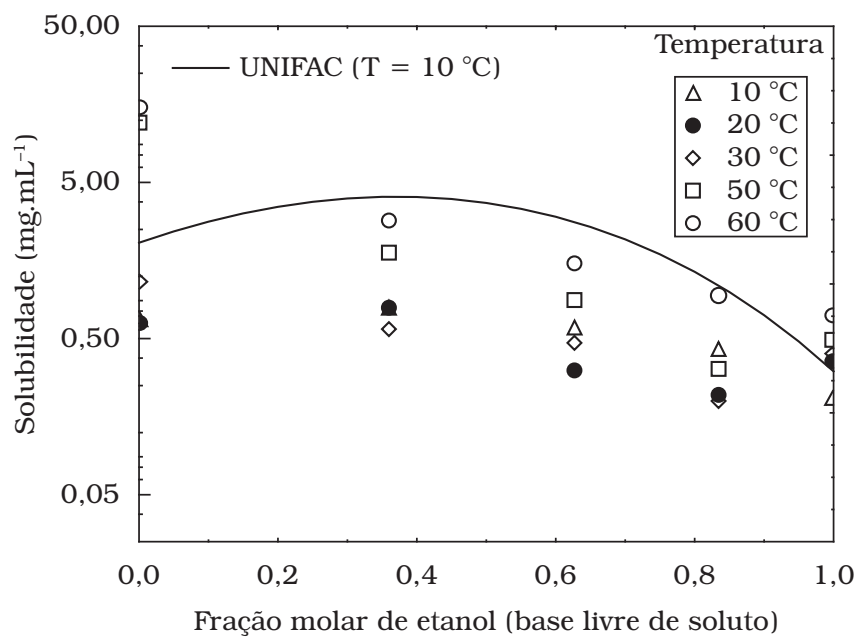

Figura 5. Diagrama de solubilidade (mg. $\left.\mathrm{mL}^{-1}\right)$ de $\beta$-caroteno na mistura de solventes etanol $(\mathrm{EtOH})+$ acetato de etila a várias temperaturas.

Tabela 4. Solubilidade de $\beta$-caroteno nas misturas dos solventes etanol $(\mathrm{EtOH})(1)+$ diclorometano (DCM) (2) nas temperaturas de 10, 20, 25,30 e $35^{\circ} \mathrm{C}$

\begin{tabular}{cccc}
\hline $\begin{array}{c}\text { Temperatura } \\
\left({ }^{\circ} \mathrm{C}\right)\end{array}$ & $\begin{array}{c}\text { Proporção de etanol: } \\
\text { diclorometano }\left(\mathrm{v} \cdot \mathrm{v}^{-1}\right)\end{array}$ & $\begin{array}{c}\text { Solubilidade } \\
\left(\mathrm{mg} \cdot \mathrm{mL}^{-1}\right)\end{array}$ & $\begin{array}{c}\text { Desvio Padrão } \\
\left(\mathrm{mg} \cdot \mathrm{mL}^{-1}\right)\end{array}$ \\
\hline 10 & $3: 1$ & 0,147 & $\pm 0,081$ \\
& $1: 1$ & 0,587 & $\pm 0,192$ \\
& $1: 3$ & 2,333 & $\pm 0,273$ \\
\hline 20 & $3: 1$ & 0,413 & $\pm 0,076$ \\
& $1: 1$ & 0,747 & $\pm 0,145$ \\
& $1: 3$ & 3,740 & $\pm 0,347$ \\
\hline 25 & $3: 1$ & 0,467 & $\pm 0,205$ \\
& $1: 1$ & 0,720 & $\pm 0,220$ \\
& $1: 3$ & 4,940 & $\pm 0,399$ \\
\hline 30 & $3: 1$ & 0,533 & $\pm 0,234$ \\
& $1: 1$ & 1,393 & $\pm 0,404$ \\
& $1: 3$ & 6,653 & $\pm 0,253$ \\
\hline 35 & $3: 1$ & 0,487 & $\pm 0,337$ \\
& $1: 1$ & 1,433 & $\pm 0,099$ \\
& $1: 3$ & 8,060 & $\pm 0,280$ \\
\hline
\end{tabular}

destes resultados, pode-se verificar um aumento da solubilidade do $\beta$-caroteno em relação ao aumento da temperatura e na proporção de diclorometano para a grande maioria das condições experimentais estudadas. Com o intuito de explicitar a aplicação do modelo UNIFAC, valores previstos na isoterma de $35^{\circ} \mathrm{C}$ são também dispostos na referida figura, demonstrando o potencial qualitativo do método de contribuição de grupos para a estimativa do coeficiente de atividade do soluto.

\section{Mistura acetato de etila + diclorometano (DCM)}

Os valores de solubilidade de $\beta$-caroteno nas misturas dos solventes acetato de etila + diclorometano estão reportados na Tabela 5 e representados na Figura 7. A partir de tais resultados pode-se verificar um incremento da solubilidade do $\beta$-caroteno em função da temperatura e com o aumento da proporção de

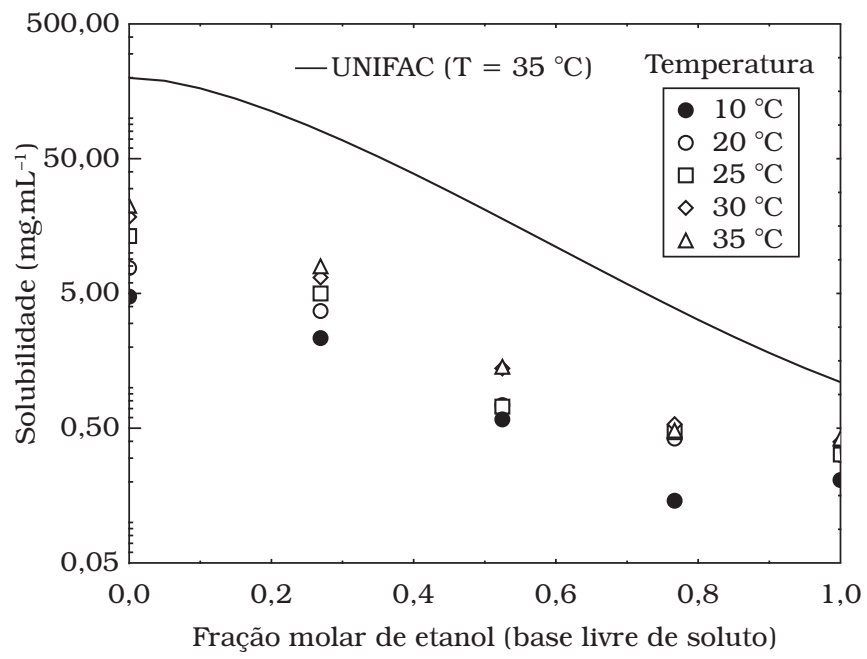

Figura 6. Diagrama de solubilidade $\left(\mathrm{mg} \cdot \mathrm{mL}^{-1}\right)$ de $\beta$-caroteno na mistura de solventes etanol $(\mathrm{EtOH})+$ diclorometano $(\mathrm{DCM})$ a várias temperaturas.

Tabela 5. Solubilidade de $\beta$-caroteno nas misturas dos solventes acetato de etila(1) + diclorometano (DCM) (2) nas temperaturas de $10,20,25,30$ e $35^{\circ} \mathrm{C}$

\begin{tabular}{cccc}
\hline $\begin{array}{c}\text { Temperatura } \\
\left({ }^{\circ} \mathrm{C}\right)\end{array}$ & $\begin{array}{c}\text { Proporção de } \\
\text { acetato de etila: } \\
\text { diclorometano }\left(\mathrm{v} .^{-1}\right)\end{array}$ & $\begin{array}{c}\text { Solubilidade } \\
\left(\mathrm{mg} \cdot \mathrm{mL}^{-1}\right)\end{array}$ & $\begin{array}{c}\text { Desvio } \\
\text { padrão } \\
\left(\mathrm{mg}^{\left.-\mathrm{mL}^{-1}\right)}\right.\end{array}$ \\
\hline 10 & $3: 1$ & 0,420 & $\pm 0,246$ \\
$1: 1$ & 0,993 & $\pm 0,031$ \\
$1: 3$ & 1,847 & $\pm 0,141$ \\
\hline 20 & $3: 1$ & 1,547 & $\pm 0,099$ \\
& $1: 1$ & 1,507 & $\pm 0,225$ \\
& $1: 3$ & 3,613 & $\pm 0,050$ \\
\hline 35 & $3: 1$ & 1,320 & $\pm 0,125$ \\
& $1: 1$ & 1,927 & $\pm 0,130$ \\
& $1: 3$ & 4,733 & $\pm 0,253$ \\
\hline 30 & $3: 1$ & 1,467 & $\pm 0,415$ \\
& $1: 1$ & 2,193 & $\pm 0,656$ \\
& $1: 3$ & 5,780 & $\pm 0,191$ \\
\hline 35 & $3: 1$ & 2,393 & $\pm 0,220$ \\
& $1: 1$ & 3,913 & $\pm 0,330$ \\
& $1: 3$ & 7,733 & $\pm 0,280$ \\
\hline
\end{tabular}

diclorometano para quase todas as condições experimentais investigadas.

Cabe notar que os valores observados de solubilidade do $\beta$-caroteno para as misturas de solventes em comparação aos valores registrados para os solventes puros permitem inferir que não houve efeito de sinergia significativo entre os solventes investigados nas condições experimentais estudadas neste trabalho. A aplicação do método UNIFAC para este sistema, a exemplo das demais misturas, atesta sua utilidade como ferramenta para previsão qualitativa.

A partir dos resultados apresentados na Tabela 5 e na Figura 7 pode-se verificar um incremento da solubilidade do $\beta$-caroteno em função da temperatura e com o aumento da proporção de diclorometano para quase todas as condições experimentais investigadas. 


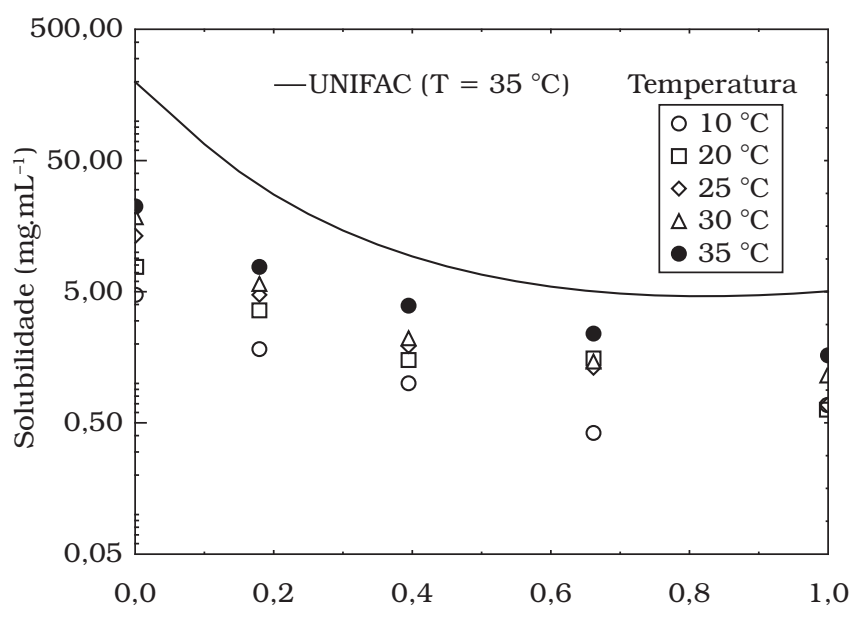

Fração molar de acetato de etila (base livre de soluto)

Figura 7. Diagrama de solubilidade $\left(\mathrm{mg} \cdot \mathrm{mL}^{-1}\right)$ de $\beta$-caroteno na mistura de solventesacetato de etila + diclorometano (DCM) a várias temperaturas.

Cabe notar que os valores observados de solubilidade do $\beta$-caroteno para as misturas de solventes em comparação aos valores registrados para os solventes puros permitem inferir que não houve efeito de sinergia significativo entre os solventes investigados nas condições experimentais estudadas neste trabalho. A aplicação do método UNIFAC para este sistema, a exemplo das demais misturas, atesta sua utilidade como ferramenta para previsão qualitativa.

\section{Conclusões}

Neste trabalho empregou-se o método gravimétrico para determinar a solubilidade de $\beta$-caroteno em solventes puros e em misturas de solventes orgânicos em diversas condições de temperatura e proporções de solventes. De maneira geral, verificou-se que o aumento da temperatura, tanto para solventes puros, como para as misturas de solventes, acarretou em um aumento da solubilidade do $\beta$-caroteno para todas as condições experimentais. Observou-se ainda, que os solventes que apresentam valores de parâmetros de solubilidade mais próximos do exibido pelo soluto conduziram aos maiores valores de solubilidade. Nas condições de temperatura estudadas, verificou-se não haver sinergismo significativo para as misturas de solventes quando comparadas aos valores de solubilidade obtidos para os solventes puros. A previsão da solubilidade através do método UNIFAC de contribuição de grupos demonstrou ser uma ferramenta com potencial efetivo para representar o comportamento dos sistemas investigados. Os resultados obtidos neste trabalho podem ser de grande valia visando à proposição e estabelecimento de processos alternativos de formação de micro/nano partículas e o encapsulamento de compostos de relevância para a indústria de alimentos, bem como podem servir de subsídios para a seleção de solventes e temperatura para extração de carotenóides produzidos em processos fermentativos.

\section{Referências bibliográficas}

1. AMBRÓSIO, C. L. B.; SIQUEIRA CAMPOS, F. A. C.; FARO, Z. P. Carotenóides como alternativa contra a hipovitaminose A. Revista de Nutrição, v. 19, n. 2, p. 233-243, 2006.

2. BARTON, A. F. M. Solubility parameters. Chem. Rev., v. 75, n. 6, p. 731-753, 1977.

3. COLDITZ, G. A. et al. Increased green and yellow vegetable intake and lowered cancer deaths in an elderly population. Am. J. Clin. Nutr., v. 41, p. 32-36, 1985.

4. CRAFT, N. E.; SOARES JR., J. H. Relative solubility, stability and absorptivity of lutein and $\beta$-carotene in organic solvents. J. Agric. Food Chem., v. 40, n. 3, p. 431-434, 1992.

5. CUTLER, R. G. Carotenoids and retinol: their possible importance in determining longevity of primate species. Proc. Natl. Acad. Sci., v. 87, n. 23, p. 7627-7631, 1984.

6. FONTANA, J. D. et al.Carotenóides cores atraentes e ação biológica. J. Biological Chem., v. 232, p. 15574-15586, 1997.

7. FRASER, P. D.; BRAMLEY, P. M. The biosynthesis and nutritional uses of carotenoids. Progress in Lipid Research, v. 43, n. 3, p. 228-265, 2004.

8. GAZIANO, J. M. et al. $\beta$-Carotene and heart disease. Circulation, v. 82, n. 3, p. 796, 1990.

9. HARTONO, R.; MANSOORI, G. A.; SUWONO A. Prediction of solubility of biomoleculesin supercritical solvents. Chem. Eng. Sci., v. 56, n. 24, p. 6949-6958, 2001.

10. HE, W. Z. et al. Precipitation of ephedrine by SEDS process using a specially designed prefilming atomizer. J. Supercritical Fluids, v. 31, n. 1, p. 101-110, 2004.

11. HONG, L. et al. Precipitation of microparticulate organic pigment powders by a supercritical antisolvent process. Ind. Eng. Chem. Res., v. 39, n. 12, p. 4882- 4887, 2000.

12. LADISLAV, F. et al. Realiability of carotenoids analyses: A review. Current Analytical Chemistry, v. 1, n. 1, p. 93-102, 2005.

13. MARASCO, E.; SCHMIDT-DANNERT, C. Towards the biotechnological production of aroma and flavour compounds in engineered microorganisms. Applied Biotechnology, Food Science and Policy, v. 1, n. 3, p. 145-157, 2003.

14. MOZSIK, G. et al. Interrelationships between the gastric cytoprotective effects of vitamin a and $\beta$-carotene and the gastric mucosal superoxide dismutase activity in rats. Acta Phys. Hung., v. 64, p. $315-318,1984$

15. OLIVIER, J.; PALOU, A. Chromatographic determination of carotenoids in foods. J. Chromatography A, v. 881, n. 1-2, p. 543-555, 2000.

16. PETO, R. et al. Can dietary 3-carotene materially reduce human cancer rates? Nature, v. 290, p. 201-208, 1981.

17. PFANDER, H. Key to Carotenoids. $2^{\text {nd }}$ ed. Birkhauser, Basel, 1987.

18. PRAUSNITZ, J. M.; LICHTENTHALER, R. I.; GOMES DE AZEVEDO, E. J. Molecular Thermodynamics of Fluid Phase Equilibria. Prentice Hall, $3^{\text {rd }}$ edition, 1999.

19. RAMALHO, R. A.; FLORES, H.; SAUNDERS, C. Hypovitaminose A no Brasil: um problema de saúde pública. Rev. Panam. Salud Publica, v. 12, p. 117-122, 2002.

20. RANTAKYLÄ, M. et al. The effect of initial drop size on particle size in the supercritical antisolvent precipitation (SAS) technique. J. Supercritical Fluids, v. 24, n. 3, p. 2510-263, 2002. 
21. RATLEDGE, C.; EVANS, C. T. Lipids and their metabolism. In: Rose, A. H.; Harrison, J. S. The yeasts: metabolism and physiology of yeasts. v. 3, $2^{\text {nd }}$ ed. Academic Press, Oxford, UK, 1989.

22. REVERCHON, E. et al. Pilot scale micronization of amoxicillin by supercritical antisolvent precipitation. J. Supercritical Fluids, v. 26, n. 1, p. 1-7, 2003.

23. RIBEIRO, H. S. et al. Preparation of nanodispersions containing $\beta$-carotene by solvent displacement method. Food Hydrocolloids, v. 22 , n. 1 , p. $12-17,2008$.

24. SABIO, E. et al. Lycopene and $\beta$-carotene extraction from tomato processing waste using supercritical $\mathrm{CO}_{2}$. Ind. Eng. Chem. Res., v. 42, n. 25, p. 6641-6646, 2003.
25. SANDLER, S. I. Chemical and Engineering Thermodynamics. John Wiley \& Sons, Inc., $3^{\text {rd }}$ edition, 1998.

26. SUBRA, P. et al. Extraction of $\beta$-carotene with supercritical fluids: experiments and modeling. J. Supercritical Fluids, v. 12, n. 3 , p. 261-269, 1998.

27. WEIDLICH, U; GMEHLING, J. A modified UNIFAC model. 1. Prediction of VLE, $\mathrm{h}^{\mathrm{E}}$, and $\gamma_{\infty}$. Ind. Eng. Chem. Res., v. 26, n. 7, p. 1372-1381, 1987. 